\title{
REFLEXÕES SOBRE A AVALIAÇÃO FINAL DE UMA DISCIPLINA ELETIVA \\ http://dx.doi.org/10.5902/2318133820506
}

\author{
Fellipe Eloy Teixeira Albuquerque \\ Universidade Federal de São Paulo - campus Guarulhos, Brasil.
}

\begin{abstract}
Resumo
Com carga horária de 60 horas a disciplina eletiva do curso de Mestrado Acadêmico em História da Arte, da Unifesp - campus de Guarulhos, possibilitou muitas questões acerca de como a relação entre Arte e Filosofia foram apreendidas durante a História. A consulta de diversos autores como Alain Badiou, Martin Heidegger, Giorgio Agambem e Jacques Rancière ajudaram na compreensão desse processo, assim como a produção artística de propositores como Vik Muniz, Peter Greenaway e Ngwenya. Para a avaliação final desta disciplina os professores responsáveis solicitam a elaboração de um texto que, a partir das referências trabalhadas em aula, ajudassem o aluno a formular um conceito de Arte. Esse artigo vem reunir as principais reflexões levantadas durante todo o processo de avaliação da disciplina que conceituou uma possibilidade de entender a História da Arte

Palavras-chave: avaliação, arte, filosofia.
\end{abstract}

\section{REFLECTIONS ON THE FINAL EVALUATION OF A DISCIPLINE ELECTIVE}

\begin{abstract}
With a workload of 60 hours to elective Academic Master's course in History of Art, Unifesp Campus Guarulhos, enabled many questions about how the relationship between Art and Philosophy were seized during history. Consultation of various authors such as Alain Badiou, Martin Heidegger, Giorgio Agambem and Jacques Rancière helped in understanding this process, as well as the artistic production of proposers as Vik Muniz, Peter Greenaway and Ngwenya. For the final evaluation of this discipline the responsible teachers requested the preparation of a text which, from references worked in class, help the student to formulate a concept of Art. This article is to bring together the main reflections raised during the evaluation process of discipline that conceptualized a chance to understand the History of Art.

Key-words: evaluation, art, philosophy.
\end{abstract}




\section{Resposta à questão única}

Tendo como exigência no Programa de Pós-Graduação em História da Arte, os alunos ingressantes precisam disponibilizar tempo para efetuar o cumprimento de certa contagem de créditos. No programa em questão os responsáveis sugerem que isso seja feito no primeiro ano de curso, quando o aluno cumpriria totalmente os créditos referentes a cinco disciplinas, sendo que duas dessas são obrigatórias. Já no primeiro ano de implantação do programa o corpo docente ofereceu aos estudantes a possibilidade de inscreverem na disciplina eletiva Arte, Filosofia, História, vincula da à linha de pesquisa Arte, Filosofia e Política, a qual concentra o menor número de professores e que, portanto, também tem as vagas mais concorridas.

Com carga horária de 60 horas, a disciplina eletiva do curso de Mestrado Acadêmico em História da Arte, da Unifesp - campus de Guarulhos, aborda muitas questões acerca de como a relação entre Arte e Filosofia foi compreendida no decorrer do tempo. Autores diversos como Alain Badiou, Marc Heidegger, Giorgio Agambem e Jaques Rancière ajudaram na compreensão desse processo, assim como a produção artística de propositores como Vik Muniz, Peter Greenaway e Ngwenya. Para a avaliação final dessa disciplina os professores responsáveis solicitaram a elaboração de um texto que, ao abordar as referências trabalhadas em aula, ajudassem o aluno a formular um conceito de Arte. Por conta do projeto de pesquisa buscou-se formular o conceito de Arte para o contexto contemporâneo, o que, evidentemente, o delimita em meio ao conteúdo trabalhado em aula.

A relação entre Arte e Filosofia é uma das mais complexas e as aulas da disciplina eletiva Arte, Filosofia, História, ministradas pela professora Carolin Overhoff Ferreira foi uma próspera iniciativa de esclarecimentos e provocações para os alunos. As aulas foram organizadas a partir de referenciais diversificados, como consulta a livros, entrevistas, animações, filmes e visitas à galeria.

A propósito, a aula referente à visita à Galeria White Cube ficou marcada para ocorrer no dia dessa avaliação, o que trouxe contribuições concretas para essa discussão. Além disto, os estudantes se viram estimulados com a visita à exposição Paintings, de Anselm Kiefer, que aconteceu entre 7 de abril e 20 de junho de 2015. As pinturas de Kiefer fazem referência ao Plano Morgenthau ${ }^{1}$ e exploram temas de história, política e paisagem, ou seja, de temas que importam a todos os envolvidos na disciplina.

A proposta inicial da ementa do curso, que era "interrogar a disciplina de história da arte em seus procedimentos de conhecimento, modelos discursivos e categorias de pensamento" (Unifesp), foi amplamente trabalhada, mostrando as possibilidades de interpretação do conceito de Arte. Tal conceito é parte da avaliação final dos

\footnotetext{
1 Projeto organizado pelos Estados Unidos após a Segunda Guerra para comprometer a economia alemã, transformando o país em uma nação pré-industrial, agrícola e evitar que a Alemanha entrasse novamente em guerra. Por conta disso o artista retornou para a representação da paisagem rural e um de seus principais símbolos: flores desabrochando.

Regae: Rev. Gest Aval Educ. Santa Maria

\begin{tabular}{l|l} 
n. 10 & Jul./dez. 2016
\end{tabular}

p. $45-53$
} 
estudantes, que devem defini-lo a partir das referências diversificada pertencentes à disciplina em questão. A princípio comecei comparando dois textos que contribuíram de forma mais contundente para todo o processo de desconstrução do conhecimento a partir dos modelos discursivos, para depois me referir aos filmes, vídeos e animações.

\section{Os textos}

O primeiro texto em ordem de relevância é o Pequeno manual de inestética (2002) do francês Alain Badiou. O autor acredita que há um vínculo entre Arte e Filosofia, mas não um vínculo imutável e rígido, um laço que constantemente é alterando. Essas alterações podem ser enquadradas dentro de três modelos centrais: didatismo, romantismo e classicismo.

O primeiro desses modelos ou esquemas, como o autor prefere se referir ao conjunto de acordos e convenções estéticas é caracterizado pela representação mimética, glorificada pelos antigos gregos. Esse esquema é praticamente fundamentado a partir da premissa imitativa da verdade, ou melhor, da imitação do efeito de verdade. Nessa perspectiva, a Arte tem atribuição meramente instrumental, está a serviço da educação, ou seja, faz parte da didática - daí o nome Didatismo - e esta, consequentemente, é normatizada pela Filosofia.

Enquanto o essencial para o Didatismo é o controle da Arte, para o Romantismo o que mais importa é o efeito inverso disso. Nesse segundo modelo a Arte é considerada a única possibilidade de desvendar a verdade, não imita o efeito, mas o produz. O que a Arte faz de fato no Romantismo é executar tudo aquilo o que a Filosofia apenas indica: ela por si própria tem o poder de educar sem necessidade de se submeter à Filosofia como normatizadora da verdade. Nesse esquema "a arte é o absoluto como sujeito, é a encarnação" da verdade (Badiou, 2002, p. 13).

Entre o desdém didático e a reverência romântica existe um período caracterizado por outra norma: o Classicismo, uma espécie de tratado de paz assinado por Aristóteles que trouxe tranquilidade também para filósofos como Descartes, Leibniz ou Espinosa. Esse esquema sustentado por Aristóteles se equilibra a partir do discurso do primeiro esquema - Didatismo - sem se aprofundar tanto na glorificação da arte do segundo - Romantismo -, mas faz um contraponto desqualificando o menosprezo do primeiro modelo. Desse modo, Badiou (2002) cita duas teses para enquadrar esse terceiro esquema: a) A arte- como sustenta o esquema didático- é incapaz da verdade, sua essência é mimética, sua ordem, a da aparência. b) Isso não é grave (ao contrário do que acredita Platão). Não é grave, porque o destino da arte não é nem de longe a verdade. (p. 14)

Nesse último esquema o que realmente importa é o efeito terapêutico da Arte, nem da cognição, muito menos do esclarecimento, mas sim do encantamento que ela pode gerar. A Arte não dependente da teoria filosófica, mas da teoria estética. 0 encantamento - agradar - pelas as aparências é o que supostamente manteve o equilíbrio entre Arte e Filosofia, isso porque no esquema clássico há distinção entre verdade e verossimilhança, sendo a Arte responsável apenas de abordar essa última.

Para nos ajudar a entender cada um desses esquemas o autor recapitula algumas questões primordiais: 
Didatismo, romantismo, classicismo são os esquemas possíveis do entrelaçamento entre arte e filosofia, o terceiro termo correspondendo à educação dos sujeitos, particularmente da juventude. No didatismo, a filosofia entrelaça-se com a arte na modalidade de uma vigilância educativa de seu destino extrínseco ao verdadeiro. No romantismo, a arte realiza na finitude toda a educação subjetiva da qual a infinidade filosófica da Idéia é capaz. No classicismo, a arte capta o desejo e educa sua transferência pela proposta de uma aparência de seu objeto. Aqui, a filosofia só é convocada enquanto estética - dá sua opinião sobre as regras do "agradar". (Badiou, 2002, p. 15)

A contribuição de Badiou (2002) é para a compreensão da relação entre Arte e Filosofia ou, em outras palavras, de como o apelo à verdade e o emprego da verossimilhança em ambas as disciplinas tornaram possível a representação da natureza pelo imaginário ocidental. $\mathrm{O}$ autor ainda ressalta a impossibilidade que a cultura ocidental encontrou até no final do século $20^{2}$ em desenvolver um novo esquema capaz de entrelaçar essas duas disciplinas. Para ele tudo indica que a saturação desses três modelos contribuiu para o "desrelacionamento" (p. 18) entre os termos provocando, sobretudo, a queda do tema educativo.

Essa queda é o que abriu caminho para as vanguardas artísticas, que foram experiências de salvaguardas da arte contemporânea, consideradas tentativas de resgate, tornando em si um esquema misto ente o didático-romântico, que segundo Badiou (2002) foi o único esquema tentado em tal século. Sendo assim, as vanguardas

foram didáticas por seu desejo de dar um fim à arte, pela denúncia de seu caráter alienado e inautêntico. Românticas também, pela convicção de que a arte deveria renascer de imediato como absolutez, como consciência integral de suas próprias operações, como verdade imediatamente legível de si mesma. Consideradas como proposta de um esquema didático-romântico, ou como absolutez da destruição criadora, as vanguardas eram, antes de mais nada, anticlássicas. ( $p$. 19)

Clássico, didático e romântico tem em comum a relação com a verdade, e hoje sem mais as vanguardas espera-se um novo esquema, que a princípio deve negar esse aspecto em comum. A Filosofia é a intermediária dos encontros entre as artes e as verdades e a arte, depois das vanguardas, passou a ser uma produtora de verdades, verdades sobre sua própria existência (Badiou, 2002). O que o autor quer nos dizer é que a Arte é conceitual, assim como a Filosofia é conceitual.

E se considerarmos a arte conceitual então, inevitavelmente, precisamos recorrer a outro autor, Jaques Rancière, com o livro $A$ partilha do sensível (2009). Esse autor, que também discute em $O$ espectador emancipado (2012) a importância da participação do espectador para a arte contemporânea, então tida como conceitual, nesse texto defende o indivíduo como um ente político e, nesse caso, "a política ocupa-se do que se vê e do que se pode dizer sobre o que é visto, de quem tem competência para ver e qualidade para dizer, das propriedades do espaço e dos

2 Época de publicação de seu texto original, portanto, não significa que agora no começo do século 21 isso já tenha mudado.

Regae: Rev. Gest. Aval. Educ. 
possíveis do tempo" (Rancière, 2009, p. 17). Para tanto, o homem político só poderá compreender ou efetuar todo esse processo se ele já estiver emancipado como espectador.

O conceito de espectador emancipado está pautado nessa referência de postura, que "põe a questão do espectador no cerne da discussão entre arte e política" (Rancière, 2012, p. 8). A proposta de reflexão apresentada pelo autor vem sendo construída desde seu livro $O$ mestre ignorante (2002), com o desenvolvimento da ideia de emancipação intelectual baseada na teoria de Joseph Jacotot, "que causara escândalo no início do século XIX ao afirmar que um ignorante pode ensinar a outro ignorante aquilo que ele mesmo não sabe, ao proclamar a igualdade das inteligências" (Rancière, 2012, p. 7). Porém, Rancière (2012), fazendo referência ao teatro, lembra que segundo a perspectiva dos acusadores

é um mal ser espectador, por duas razões. Primeiramente, olhar é o contrário de conhecer. O espectador mantém-se diante de uma aparência ignorando o processo de produção dessa aparência ou a realidade por ela encoberta. Em segundo lugar, é o contrario de agir. O espectador fica imóvel em seu lugar, passivo. Ser espectador é estar separado ao mesmo tempo da capacidade de conhecer e do poder de agir. (p. 8)

Algumas das novas formas de manifestações da arte contemporânea tentam burlar essa afirmativa e, seguindo o exemplo do teatro, desconsiderando a concepção da quarta parede. Rancière (2012) refere sobre duas fórmulas empregadas no teatro para a eliminação desse limite imaginário: uma funciona a partir da comoção, sendo mostrado para ele "um espetáculo, estranho inabitual, um enigma cujo sentido ele precise buscar. Assim será obrigado a trocar de posição de espectador passivo pela de inquiridor ou experimentador científico que observas os fenômenos e busca suas causas" (p. 9). A outra fórmula pressupõe que é essa própria distância que deve ser abolida, "o espectador deve ser retirado da posição de observador que examina calmamente o espetáculo que lhe é oferecido" (Rancière, 2012, p. 9).

Todos os outros textos contribuíram para a formulação de um conceito novo para a Arte, mas a escolha desses dois autores é propositalmente direcionada, pois é sobre a arte contemporânea que 0 meu projeto de pesquisa se concentra. Por conta desse mesmo fato, os vídeos que usaremos para fundamentar esse novo conceito seguem o mesmo critério.

\section{Os filmes}

Os filmes Lixo extraordinário (2009), The great contemporary art bubble (2009) e Återtråffen (2013) são, dentre todos os filmes, animações e vídeos utilizados em aula, os que melhor se encaixam para pensar a arte numa perspectiva contemporânea. $O$ primeiro filme dessa lista não foi exibido, mas foi constantemente citado pela professora por abordar temas interdisciplinares e por expor algumas das discussões que interessam a muitos outros artistas e pesquisadores sobre arte contemporânea: a relação entre arte e vida, o conceito e objeto e a concepção de arte. O segundo filme por sua vez, demonstra as relações financeiras do mercado de arte, que após grande crescimento se viu em meio de uma crise. No último filme há muito mais proposições 
poéticas que discussões sobre bullyng e superação de traumas do passado: há uma evocação de perspectiva um tanto confusa sobre as identidades culturais dos personagens, característica muitas vezes evidentes nas produções de arte contemporânea.

O filme Lixo extraordinário pode ser complementado por vários dos textos consultados, mas em particular tem um trecho que gostaria de dar relevância a ideia sobre o espectador emancipado levantada por Jaques Rancière (2012). O trecho, entre a altura de 1:18h e 1:20h do filme, mostra uma conversa entre Vik Muniz e Tião Santos sobre o gosto, após ter sido levado para uma casa de leilões, onde ouviu explicações sobre as diferentes obras de arte contemporânea expostas pelos corredores do recinto. Nessa cena o então catador e líder da Associação dos Catadores do Aterro Metropolitano de Jardim Gramacho foi indagado pelo artista plástico sobre o que ele havia achado das obras. Tião, em primeiro momento, reconheceu sua dificuldade em entender os propósitos das representações abstratas, mas admitiu que após ter ouvido as explicações e entender do que se tratava começou a gostar. Vik Muniz completou a sentença com a frase: "De repente é falta de conhecimento que nos faz não gostar das coisas?".

Em 2008 as principais nações passaram por uma crise econômica de caráter mundial, afetando vários segmentos da vida cotidiana. No mundo das artes não foi diferente. O diretor Ben Lewis tentou, no documentário The great contemporary art bubble, compreender e explicar por que depois de cinco anos em alta o mercado enfrentou um boom nos preços, que consequentemente desestabilizou os investimentos com uma queda posterior de até $50 \%$.

Esse caso demonstra não só uma falta de interesse proposital dos mediadores no mercado de arte mundial, mas também de como esse mercado se insere num jogo de estratégias em que o interesse é intercambiado de acordo com fatores externos. Para entender melhor esse processo de circulação de interesses, precisamos compreender o próprio mercado de arte e sua organização, para tanto recorreremos às duas referências, Anne Cauquelin (2010) e Alain Quemin (2014).

Cauquelin (2010), ao discutir sobre a arte contemporânea, organiza um discurso em torno da estrutura que possibilitou seu aparecimento desde a modernidade. Para isso, compara o sistema das artes modernistas e contemporâneas com um regime, e no segundo caso, ao regime da comunicação. Ambos - sistemas e regimes - são orientados a partir das seguintes primícias:

Em primeiro lugar, a noção de $<<$ rede $>>$ : redes interligadas e metaredes. Seguem-se: 2/ o looping ${ }^{3}$, ou autonomia; $3 /$ a redundância, ou saturação da rede; 4/ a nomeação ou prevalência do recipiente (a rede) sobre o conteúdo; 5 / a construção de uma realidade em segundo grau, ou simulação. (Cauquelin, 2010, p. 41)

São esses cinco conceitos alinhados e funcionando normalmente, cada qual com sua função, que possibilitam a permanência e a manutenção do mercado. Sendo que a rede corresponde ao funcionamento do sistema, com características dependentes e

\footnotetext{
${ }^{3}$ Referência à topologia da rede, cujos componentes são conectados em rede de tal forma que o último componente é ligado ao primeiro componente. 
expansionistas, é ligada a outros canais tecnológicos permitindo a circulação das informações e produtos ${ }^{4}$. O looping é a própria circulação da rede, a impossibilidade de se destacar do sistema, a possibilidade de reversibilidade. A redundância ou saturação da rede é a consequência do looping, a válvula de escape que indica o momento de sair de cena. A denominação, por sua vez, funciona como remédio para os efeitos da saturação, é o conceito aplicado para diferenciar aquilo que está sendo feito a partir de uma identidade, de uma particularidade. Por fim, a construção da realidade é uma referência à linguagem empregada na rede que pouco se importa coma distinção entre verdade e falsidade: esse último conceito serve, principalmente, para construir um mecanismo de apreensão de outro mundo das artes, ofuscando do senso comum o funcionamento desse mundo real.

$\mathrm{Na}$ descrição de Quemin (2014), o mercado da arte também acompanha todas essas características conceituais apontadas por Cauquelin (2010). Mas o autor espanhol trás uma análise importante sobre os dois principais segmentos do mercado de arte: um que afeta o valor estético e outro o financeiro. Nesse sentido, o problema do mercado de arte contemporâneo é desvendar o real valor de uma arte consagrada como contemporânea, deixando a mercê de uma dada academia informal a atividade de classificação desses valores, o que obviamente deixa de lado um grande número de outras produções plásticas atuais (Quemin, 2014).

Esse deixar de lado é um ato temporal e estratégico, afinal não dá para se valorizar tudo e ao mesmo tempo manter o sistema das artes funcionando. Por conta disso ele refere uma divisão mais ampla do mercado, entre o de arte antiga e o atual, de arte contemporânea: "Sobre o primeiro, os valores tanto estratégicos quanto financeiros estão amplamente estabilizados, ainda que as mudanças de gosto e a moda possam afetar as reputações e os preços" (Quemin, 2014, p. 13). Porém, no segundo caso a questão estética é financeira, sendo intercambiado pela íntima relação entre o mercado e o museu, "a certificação do valor estético condiciona o preço, ainda que o preço seja, por sua vez, um dos critérios de certificação do valor estético" (Quemin, 2014, p. 13).

Sendo assim, a exemplo da crise de 2008, é compreensível que se conclua, ao menos que para o circuito de arte, que a falta de interesse é um mal presente que vem para um bem futuro, ou seja, não se deve atribuir valor hoje para aquilo que não se espera adquirir ainda mais valor amanhã.

O filme sueco envolve questões ainda mais complexas, por se trata $r$ de uma produção de artista, e tem no cerne a discussão sobre definição da arte e do cinema. Como mencionado, a produção de Anna Odell trás uma analise confusa que pode ser facilmente confundida com as discussões sobre as identidades do pós-modernismo. O filme, que começa mostrando a entrada de um personagem imaginário em um conjunto de salas representando supostamente uma escola, é seguido por cenas de um encontro de amigos, em que a protagonista aparece sem ser convidada e profere um discurso que desagrada a todos ao ponto dela ser hostilizada e jogada para fora do estabelecimento. $\mathrm{O}$ emblema dessa produção está no fato de não ficar claro o limite entre documentário e ficção, a diferença entre personagem e autor. Novamente, assim como no filme de Vik Muniz (2009), a relação entre arte e vida é questionada.

${ }^{4}$ Nesse caso obras de arte, artistas, ideia, conhecimentos, etc. 
No decorrer desse filme a artista/protagonista ${ }^{5}$ se reúne pessoalmente com os outros personagens que estiveram envolvidos na reunião para buscar respostas sobre o ocorrido. O desfecho dessa história é tão confuso quanto sua proposta: não fica claro se trata-se de uma discussão sobre bullyng praticado pelos seus ex-colegas de escola ou se ela era realmente insuportável para constituir amizades com outras pessoas. Porém, uma coisa fica clara à protagonista, que pode ser ou não o alter ego da artista: ela tem uma visão sobre si bem diferente daquela que o restante dos personagens.

É com esses filmes e os textos citados anteriormente que buscarei expor uma definição de arte que consegui compreender a partir das aulas que participei nessa disciplina eletiva.

\section{Considerações finais}

O que percebemos é que a relação entre Arte e Filosofia é necessária, mas que nem sempre essa relação aconteceu de forma consensual. Em certos momentos a Arte se sobressaia, enquanto a Filosofia desempenhava papel secundário, outrora era o contrário, isso quando não estavam em trégua. Por conta dessa observação acreditamos na mutabilidade da Arte, a qual jamais poderá ser considerada imutável, afinal, em cada esquema defendido por Badiou (2002) a Arte assume uma postura diante a Filosofia, ou seja, assume também um conceito.

Outra questão é que a arte pode ser definida segundo o mercado, ou segundo um sistema das artes. Quando Cauquelin (2010) refere à regimes de consumo e da comunicação, o que ela quer nos dizer é que o conceito de arte depende de um contexto social e econômico. Alain Quemin (2014), por sua vez, esclarece que a economia pode se referir não só a valores financeiros, mas também estéticos, e que esses últimos são legitimados pelos primeiros, e vice-versa.

A Arte também pode ser definida por sua relação com a vida das pessoas. Vik Muniz (2009) e Jaques Rancière (2009) nos fazem pensar sobre quanto a educação estética pode definir a concepção de Arte. A artista Anna Odell (2013) também nos provoca a interpretar sua obra como proposta de reflexão sobre as relações humanas, mas de uma forma em que a escrita sobre si mesma nos arremeta aos problemas das identidades culturais.

Com todas essas possibilidades só podemos chegar a uma definição de Arte: a Arte pode ser tudo e ao mesmo tempo nada. Pode ser tudo aquilo que nós humanos como produtores de significado podemos criar, desde lixo até filmes de leitura complexa e de sensibilidades confusas. Também pode ser nada, se não a entendermos em suas múltiplas interpretações. Em suma, assim como diz Arthur Danto: para a arte contemporânea "qualquer coisa pode ser considerada arte" (Mammì, 2012, p. 21), isso desde que, para quem a arte está sendo apresentada já esteja educado para sentir, mas pode continuar sendo nada para quem não a reconheça ainda. O conceito transitório de Arte é um acordo entre o artista, os mediadores e o espectador: se algo não funcionar com um desses sujeitos a definição pode mudar. Dizer o que a Arte é depende muito de para quem é. Porém, como ela

${ }^{5}$ A personagem tem o mesmo nome que a autora do filme.

\begin{tabular}{|l|l|l|l|l|r|}
\hline Regae: Rev. Gest. Aval. Educ. & Santa Maria & v. 5 & n. 10 & Jul./dez. 2016 & p. $45-53$
\end{tabular} 
está é mais fácil: a arte está em constante mudança. E ainda, se por acaso estiver equivocado e arte não estiver em constante mudança, então faz parte da mudança ou é ela mesma a própria mudança.

\section{Referências}

BADIOU, Alain. Pequeno manual de inestética. São Paulo: Estação Liberdade, 2002. CAUQUELLIN, Anne. Arte contemporânea. Mem Martins: Europa-America, 2010.

DANTO, Arthur. Após o fim da arte: a arte contemporânea e os limites da história. São Paulo: Odysseus, 2006.

MAMMì, Lorenzo. O que resta da arte. São Paulo: Cia das Letras, 2012.

QUEMIM, Alain. Evolução do mercado de arte: internacionalização crescente e desenvolvimento da arte contemporânea. In: MORAES, Angélica de; FIALHO, Ana Letícia; QUEMIN, Alain. O valor da obra de arte. São Paulo: Metalivros, 2014, p. 10-31. RANCIÈRE, Jacques. O espectador emancipado. São Paulo: Martins Fontes, 2012. RANCIÈRE, Jacques. A partilha do sensível: estética e política. São Paulo: 34, 2009. RANCIÈRE, Jacques. O mestre ignorante: cinco lições sobre a emancipação intelectual. Belo Horizonte: Autêntica, 2002.

LEWIS, Ben. The great contemporary art bubble. Reino Unido: Ben Lewis TV Company, 2009. Disponível em <https://distrify.com/films/6542>. Acesso em 1 maio. 2015.

ODELL, Anne. Återträffen 2013 Svensk Dramafilm HELA FILMEN. Disponível em <https://www.youtube.com/watch?v=--6W7wnFEls>. Acesso em 13 jun. 2015.

WALKER, Lucy. Lixo extraordinário: Reino Unido, Brasil: Almega Projects; O2 Filmes, 2009.

GALERIA WHITE CUBE. Exhibitions: Anselm Kiefer Paintings. Disponível em: <http://whitecube.com/exhibitions/anselm_kiefer_sao_paulo_2015>. Acesso em 14 jun. 2015.

UNIVERSIDADE FEDERAL DE SÃO PAULO. GRADUAÇÃO /AFH 2015_1: Ementa da disciplina eletiva: Arte, Filosofia e História. Disponível em <http://ead.unifesp.br/graduacao/course/view.php?id=2666>. Acesso em 13 jun. 2015.

Fellipe Eloy Teixeira Albuquerque é estudante do curso de Mestrado em História da Arte pelo PPGHA Unifesp - campus de Guarulhos.

Endereço: Rua João Portela Sobrinho, 430 - 18540-000 - Porto Feliz - SP Brasil.

E-mail: fellipe.eloy@gmail.com.

Recebido em 21 de novembro de 2015.

Aceito em 17 de março de 2016. 